\title{
Fulfilment of expectations mediating quality and satisfaction: the case of hospital service
}

\author{
Frederic Marimon $^{\mathrm{a}}$, Dolors Gil-Doménech ${ }^{\mathrm{b} *}$ and Ramon Bastida ${ }^{\mathrm{c}}$ \\ ${ }^{a}$ Department of Economy and Business Organisation, Universitat Internacional de \\ Catalunya, Immaculada 22, 08017 Barcelona, Spain. Phone: +34 932541 800. Email: \\ fmarimon@uic.es ORCID iD: 0000-0002-5572-7341 \\ $b^{*}$ Department of Economy and Business Organisation, Universitat Internacional de \\ Catalunya, Immaculada 22, 08017 Barcelona, Spain. Phone: +34 932541 800. Email: \\ mdgil@uic.es ORCID iD: 0000-0003-4397-2144 \\ ${ }^{c}$ Department of Economy and Business Organisation, Universitat Internacional de \\ Catalunya, Immaculada 22, 08017 Barcelona, Spain. Phone: +34 932541 800. Email: \\ mdgil@uic.es ORCID iD: 0000-0001-7855-727X
}

\section{Acknowledgements}

The authors are grateful to Dra. Jasmina Berbegal, vice-dean of the Economics and Social Sciences Faculty of the Universitat Internacional de Catalunya, who provided insight and expertise that greatly assisted our research. We sincerely appreciate her guidance. 


\title{
Fulfilment of expectations mediating quality and satisfaction: the case of hospital service
}

\author{
Many attempts have been conducted during the last decades to define a quality \\ measurement scale in the health sector, however there is not yet a complete \\ agreement on which dimensions impact satisfaction. Besides, a quality scale \\ encompassing all patient concerns related to his/her hospitalisation is still lacking. In \\ this context, the purpose of this study is three aimed: (i) defining a scale (HospQual) \\ to assess patients' perceived quality of hospital service; (ii) analysing the impact of \\ perceived quality on patient satisfaction; and (iii) analysing the mediation role of \\ fulfilment of patients' expectations between quality and satisfaction. To capture data \\ regarding Catalan patients' perceived quality of hospital service, two surveys were \\ launched: the first collected 200 questionnaires in June 2016, and the second \\ collected 601 questionnaires in December 2016. An array of exploratory factor \\ analyses was carried out with the first sample to establish the HospQual scale \\ dimensions, which showed appropriate psychometric characteristics. The second \\ sample was used for confirmatory purposes and also to analyse the research model \\ analysis addressed to determine the mediating role of fulfilment of expectations. \\ Findings confirmed HospQual dimensions impact satisfaction. Additionally, \\ fulfilment of expectations is proved to be a mediator between quality and \\ satisfaction.
}

Keywords: hospital service quality; patient satisfaction; service quality; fulfilment of expectations

\section{Introduction}

The conceptualisation and measurement of service quality perceptions has been one of the most devoted and controversial topics in the service marketing literature up to date (Brady \& Cronin, 2001; D. Lee, 2016; Li et al., 2015). It is generally agreed that service quality is a multidimensional, higher order construct (Parasuraman, Zeithaml, \& Berry, 1988). Specifically, in the health sector there have been many attempts to define a quality 
measurement scale. In this field, Parasuraman et al. (1988) created ServQual which has turned out to be the most used scale in healthcare (Ladhari, 2009; Singh \& Prasher, 2017). Some years later Cronin and Taylor (1992) proposed the ServPerf scale, which included only performance measures. Since then, an intense debate has emerged surrounding measuring quality in health services. Particularly, many authors have attempted to define and validate multidimensional scales for that purpose (Dagger, Sweeney, \& Johnson, 2007; Haddad, Fournier, \& Potvin, 1998; Rao, Peters, \& Bandeen-Roche, 2006). Recently, Lee (2016) developed a scale, named HealthQual, with more objective and universal measurement items.

Despite the advances in perceived quality measurements, particularly for health services, all the existing scales have a very precise aim to focus on a specific health service or analyse a different point of view. This explains why there is not a complete agreement on which dimensions really have an impact on satisfaction. Moreover, a holistic quality scale that encompasses all possible patient concerns related to his/her hospitalisation is still lacking. Another notable shortcoming in current published scales is the lack of consideration of some recent phenomena, such as the use of smartphones in administrative processes and in communication between hospital and patient. Therefore, the first contribution that this study is making to the existing literature is to define and validate a scale (HospQual) to assess patients' perceived quality of hospital services. The proposed scale will be based on previous studies, on instruments already used for measuring patients' satisfaction by different governments, and on the opinion of different experts in this field. Customer satisfaction has also been an important subject in marketing literature (M. A. Lee \& Yom, 2007) and in particular, many studies have hypothesised that service quality is an antecedent to customer satisfaction (Choi, Cho, Lee, Lee, \& Kim, 2004; 
Pollack, 2009). The direct implication for managers comes when this satisfaction in its turn impacts loyalty and repurchasing behaviour (Yaya, Marimon, \& Casadesus, 2015). In particular, for the healthcare industry, patient satisfaction is of paramount importance due to the fact that in addition to the previously shown reasons, healthcare is a public service in many countries (Moliner, 2009). Aiming at testing this relationship in the heath sector, the second contribution of this paper consists on analysing the impact of perceived quality on patient satisfaction.

In healthcare, several studies have assessed the prediction qualities of fulfilment (Bjertnaes, Sjetne, \& Iversen, 2012; Palazzo et al., 2014; Pettersen, Veenstra, Guldvog, \& Kolstad, 2004). However, fulfilment has only been analysed as fulfilment of medical treatment or other partial issues. Consequently, there is no evidence yet about the role of fulfilment of expectations regarded as a whole or complete fulfilment of the service received. In an attempt to shed some new light on this issue, the third contribution that this study pursues is to analyse the mediating role of fulfilment of patients' expectations in the relationship between service quality and patient satisfaction.

The paper is structured as follows. The next section summarises the current state of affairs in assessing service quality in healthcare services, the relationship between service quality and patients' satisfaction, and the fulfilment of expectations. The section concludes with the research model. The third section includes the methodology employed in the analysis. The results are then presented and discussed. The paper ends with concluding remarks for both academics and practitioners, and includes the limitations and possible avenues for future research. 


\section{Literature review and proposed research model}

\section{Service quality scales in health}

The ServQual scale is one of the pioneering published instruments to assess service quality proposed by Parasuraman et al. (1988) and, lately, refined by the same authors (Parasuraman, Berry, \& Zeithaml, 1991). The instrument consists of five dimensions (i.e. tangibility, reliability, responsiveness, assurance and empathy), is of wide purpose and has been adapted to different industries, geographical areas and situations, and also to the health sector. Brady and Cronin (2001) proposed a hierarchical service quality model (HSQM), claiming that the construct is better conceptualised using a higher order factor-a third-order factor model that ties service quality perceptions to three dimensions: outcome, interaction, and environmental quality.

Also Dagger et al. (2007) developed a multidimensional hierarchical scale for measuring health service quality. They proposed the following four dimensions:

(1) Interpersonal quality, which reflects the relationship developed and the dyadic interplay that occurs between a service provider and a user;

(2) Technical quality, which reflects the expertise, professionalism, and competency of a service provider;

(3) Environmental quality, which comprises a complex mix of environmental features; and

(4) Administrative quality, which comprises administrative service elements that facilitate the production of the core service while adding value to a customer's use of a service. 
Several other attempts to develop more effective quality measurement scales were performed (Haddad et al., 1998; D. Lee, 2016; Sower, Duffy, Kilbourne, Kohers, \& Jones, 2001; Westbrook, Babakus, \& Grant, 2014).

In this context, the present paper proposes a renewed and fresh quality scale measurement, named HospQual, with the objective to assess the perceived quality of hospital patients who have been hospitalised at least one night. These customers are sensitive to many different dimensions: not only the strictly medical issues such as the diagnostic process or the treatment success, but also those processes related to the hostel services embodied in the whole service (i.e. the catering service or general comfort parameters). The new instrument will mix up both existing scales and instruments currently used in some official health systems in this updated construct.

\section{Service quality impact on satisfaction}

Consumer satisfaction has been a subject of much attention in the marketing literature, because of its potential influence on consumer purchase intentions and customer retention (Oliver, 1997; Raposo et al., 2009;). Oliver (1997) defined satisfaction as "the consumer's fulfilment response", a judgement that a product or service provides a pleasurable level of consumption-related fulfilment. After initial controversy, it is now clearly set that satisfaction and service quality are distinct constructs (Pollack, 2009).

Brady et al. (2002) stated that although there is a lack of consensus concerning the specification of the service quality-satisfaction relationship, the dominant conceptualisation suggests that service quality is an antecedent to the superordinate satisfaction construct. Since then, this has been proven by many authors, also in the healthcare services (Ryu, Lee, \& Kim, 2012; Thawesaengskulthai, Wongrukmit, \& Dahlgaard, 2015). Patient satisfaction 
assessment has become an integral part of healthcare organisations' strategic processes because several studies conclude that the more satisfied customers are, the greater the customer retention and willingness to recommend (Peyrot, Cooper, \& Schnapf, 1993; Zeithaml et al., 1996).

In accordance with previous studies, and in order to address the second objective of this work, which aims at determining the relationship between the two aforementioned constructs, the following hypothesis is formulated:

H1: The perceived quality impacts positively on a patient's satisfaction.

\section{Fulfilment of expectations}

The construct of fulfilment of expectations has been intensively used in different knowledge fields. Grönroos (2006) recommends using fulfilment of expectations to better understand the entire process from a firm's value proposition to customers' perception. Following this rationale, the present study proposes using this construct for the analysis of service satisfaction. Specifically, in the health setting, the fulfilment of expectations has been applied as an antecedent to patient experience. In this line, Pettersen et al. (2004) conducted a survey in Norway to assess the antecedents of satisfaction for hospital patients, and found that fulfilment of expectations regarding medical treatment is a strong predictor of patient experience. In the same vein, Bjertnaes et al. (2012) studied the effects of different predictors of overall patient satisfaction, including patient-reported experiences, fulfilment of patients' expectations, and sociodemographic variables. Their results showed that the most relevant antecedents for overall patient satisfaction in hospitals were patientreported experiences and fulfilment of expectations. On the contrary and in a similar context, Himmel et al. (1997) did not notice differences in satisfaction between patients 
whose expectations were or were not fulfilled. Lately, Palazzo et al. (2014) studied the determinants of satisfaction one year after total hip arthroplasty (THA). The authors concluded that to improve patient satisfaction after THA, a patient's expectations and fulfilment need to be carefully addressed. They also pointed out that the main postoperative determinant of satisfaction was the fulfilment of a patient's expectations. These studies provide evidence that fulfilment of expectations concerning the entire hospital service also has a mediating effect when assessing satisfaction. Accordingly, two hypotheses are proposed:

$\mathrm{H} 2$ : Perceived quality impacts positively on fulfilment of expectations.

H3: Fulfilment of expectations impacts positively on patients' satisfaction.

Both $\mathrm{H} 2$ and $\mathrm{H} 3$ pretend to give an answer to the third and last objective of this study, that is, to explore the mediation role of fulfilment of patients' expectations between quality and satisfaction.

Figure 1 shows the research model that encompasses the three hypotheses.

《Insert Figure 1 about here》

\section{Methodology}

\section{Questionnaire structure, data collection and sampling}

In order to capture data regarding patients' perceived quality of hospital services, two surveys were launched in different moments. The first one was used for the exploratory analysis of the scale and its debugging. The second was used for the confirmatory analysis 
of the quality scale and for the analysis of the full research model. The items used in both surveys are shown in the annex.

The initial questionnaire was used for the first survey, which was launched in June of 2016 and 200 questionnaires were obtained. A specialised company assisted with this collection process. The company addressed to their panel of respondents, and it was imposed that the sample should adjust to the Spanish population in terms of gender and according to age categories. Once the debugging process for the scale was performed, a second survey was launched. This second questionnaire only included those quality items which passed the debugging process in the exploratory analysis and the two additional items (satisfaction and fulfilment of expectations). This debugging process consisted on selecting the four items with largest loads for each of the four dimensions considered. The underlying reason to propose the second questionnaire was to verify the discriminant validity (which was not accomplished by the items in the first questionnaire) and to provide and easier-to-use scale, with only 18 questions.

It was launched in December of 2016 and 601 questionnaires were retained for analysis. In this case, the survey was administrated through ten surveyors that collated the sample directly by the snowball sampling technique, addressing to their personal contacts and expanding the number through the social networks till the 601 questionnaires were reached. The confirmation of the scale and the research model analysis were performed with the answers to this second survey.

In both cases respondents were people living in Catalonia that had been hospitalised at least one night during the last three years (between 2014 and 2016). This last condition for the temporal horizon of the target population was introduced to vouch for the homogeneity of the respondents' experiences and at the same time to ensure that the 
perception was accurate and not yet blurred by the time elapsed since the moment experienced. A time lapse between the experience and its evaluation introduces a memory bias that can be minimised by collecting the patient assessment as soon as possible (Pizzi, Marzocchi, Orsingher, \& Zammit, 2015).

The questionnaire used in the first survey included a section to collect 49 items related to the perceived quality of the hospital service. These items were gathered in the four dimensions used by Dagger et al. (2007), as previously described, although items borrowed from other authors such as Brady and Cronin (2001) were also included. Although the reliability of the Dagger et al. (2007) model has been fully tested, hospitals have introduced new practices and methods to interact with patients that are not assessed by previous scales. Moreover, most of Europe's economies have suffered an economic crisis since the publication of Dagger's scale, resulting in substantial cuts that have in turn impacted service standards of public hospitals. Therefore, additional new items, proposed directly by the authors were added. Some of these novelty items were suggested by a focus group that was organised to enrich the questionnaire. Some of the other new items were proposed by practitioners, scholars and experts who were interviewed by the authors. Other sources that provided some new items were the current questionnaires that the local government in Catalonia uses in its quality instrument measurement (referred to as CatSalut in the annex), an analogous instrument used by the Basque Country (referred to as Osakidetza in the annex), and finally another one used in the United States of America (referred to as Centres for Medicare \& Medicaid Services in the annex). All these items were presented as statements to which respondents indicated their agreement/disagreement on a five-point Likert-type scale (from $1=$ strongly disagree, to $5=$ strongly agree). 
The second survey included only 18 items: 16 items related with quality, one item to assess global satisfaction and another to assess fulfilment of expectations. All these 18 items are highlighted in grey in the annex.

\section{Assessing the reliability and validity of the HospQual scale}

The items were gathered a priori under the aforementioned dimensions, according to Dagger et al.'s (2007) paper. However, these dimensions had to be proven consistent in the context under study. Therefore, an array of four different exploratory factor analyses (EFA) through principal component analysis were performed to explore the four different sets of items: (i) a set of 16 items for interaction quality, (ii) a set of 12 items for technical quality, (iii) a set of 12 items for physical environment, and (iv) a set of 9 items for administration quality.

Items loading more than 0.70 were retained. The psychometric characteristics of the scale were analysed. Then, the statistics for reliability (Cronbach's alpha and composite reliability (CR) and convergent validity (average variance extracted (AVE) of these four factors were calculated, along with the discriminant analysis of the dimensions within this scale, comparing the square of its AVE with the correlations with the remaining dimensions. Nevertheless, the discriminant validity could not be proved.

In order to solve the lack of discriminant validity among dimensions, a new set of four dimensions was proposed, using a stricter criterion for retention: taking the four items with the largest loads for each dimension, resulting in a total of 16 items. The resulting scale is henceforth called the HospQual scale (see the grey items in the annex).

The statistics for reliability and convergent validity of the HospQual scale were obtained and discriminant validity was confirmed for this scale. Once all of the dimensions 
displayed correct psychometric properties, a set of confirmatory factor analyses (CFA) was performed based on the second sample. Henceforth, the analysis was conducted using the answers from the 601 short questionnaires. The CFA validated the HospQual scale.

\section{Assessing the research model: The perceived service quality impact on patient satisfaction and the mediating role of fulfilment on quality and satisfaction}

The proposed model (Figure 2), in which the dependent variable is the item "patient satisfaction", was analysed. This item was regressed by a second order factor (that in its turn is reflected in the four perceived quality dimensions of the scale) and the fulfilment of expectations. The model also allows assessing the mediation effect of the fulfilment of expectations between patient perceived quality and satisfaction.

\section{《Insert Figure 2 about here》}

Note that the labels of the quality dimensions are not exactly the same proposed by Dagger et al. (2007), but they are according to the results shown in the subsection devoted to the assessment of the scale.

In order to evaluate the mediating role of fulfilment of expectations, the methodology proposed by Baron and Kenny (1986) and Zhao et al. (2010) was used. This last step was required to provide the nomological validity of the scale, as it provided new insights into the antecedents of patient satisfaction. Analysis of the research model was conducted through structural equation modelling (SEM) methodology. 


\section{Results}

\section{Sample demographic characteristics}

Table 1 shows the demographic information of the samples as well as the characteristics of the hospitalisation.

\footnotetext{
《Insert Table 1 about here»
}

The Harman's test was then performed, taking the 49 items of the four original dimensions of perceived quality taken altogether. The factor extracted (forcing an extraction of one single factor, without rotation) explained $53.88 \%$ of all the variance. This result is slightly above the recommended threshold of 0.50 and consequently it does not provide clear evidence in any sense, for or against (regarding the multicollinearity), neither regarding to how common method bias (CMB) affects data (Podsakoff, MacKenzie, Lee, \& Podsakoff, 2003). However, the second Harman's test, performed taking the 18 items that involved in the complete research model (Figure 2) for the second sample, explained 47.19 $\%$ of variance, below the 0.50 threshold, what vouches for a lack of CMB.

\section{Assessing the reliability and validity of the HospQual scale}

Taking the first sample, four EFAs using principal component analysis were performed to investigate the unidimensionality of each of the four perceived quality dimensions. The Kaiser-Meier-Olkin statistic and the Bartlett test for the four cases forecasted a good result for these analyses. These results confirmed a linear dependence between the variables and 
supported the view that the results were sound (Hair, Black, Babin, Anderson, \& Tatham, 2010; Yaya, Marimon, \& Casadesús, 2016). Table 2 shows the suggested factors, including the percentage of variance extracted.

\section{《Insert Table 2 about here》}

The criterion to define the scale was retaining items with loads greater than 0.70 . The resulting scale contained: (i) a set of 15 items for interaction quality, (ii) a set of 10 items for technical quality, (iii) a set of 7 items for physical environment, and (iv) a set of 8 items for administration quality. This scale was referred as provisional HospQual scale, because, as explained below, a stricter criterion was taken later to define the definitive scale.

The internal reliability of the factors of the provisional HospQual scale was then assessed and confirmed as the retained indicators exhibited loadings of 0.70 or higher. The internal consistency of the constructs reaffirmed the approach presented here, and values were obtained that exceeded the recommended threshold value of 0.70 for both the Cronbach's alpha coefficient and CR. The AVEs also surpassed the cut-off point of 0.50 (Nunnally \& Bernstein, 1994) for all factors. To further corroborate the suitability of the items included, several tests removing the items with a lower load were conducted. Results revealed that the Cronbach's alpha value did not improve; therefore, the decision was not to exclude any item.

The next step consisted of an analysis of the discriminant validity of the scale, which was performed using linear correlations or standardised covariances between latent factors by examining whether the inter-factor correlations were less than the square root of 
the AVE (Fornell \& Larcker, 1981). In some cases, it was not accomplished and discriminant validity could not be verified. Aiming at covering this inconvenient, and trying also to provide a shorter and easier-to-use scale, the provisional HospQual scale was reconfigured taking the four items with the largest loads for each dimension (all of them were greater than 0.7), resulting into the definitive HospQual scale.

Table 3 summarises the new reliability analysis for the definitive HospQual scale. The internal reliability of these factors and their internal consistency were confirmed. Furthermore, their AVEs were greater than 0.50, thus vouching for convergent validity (Fornell \& Larcker, 1981).

«Insert Table 3 about here»

Paying closer attention to the four items for the first dimension (interaction quality), all of them enquire about the listening capability of doctors and nursing staff. The second dimension (technology quality) captures the knowledge of medical staff, the way they disclose interesting information about the disease, and also the way they explain the medical treatment that the patient should follow, which ensures that the patient feels safe. The remaining two brief dimensions (physical environment and administrative quality) are similar to the corresponding large dimensions. Consequently, two changes in the dimension labels are proposed, thus being as follows:

(1) Listening to the patient (instead of interaction quality).

(2) Staff knowledge (instead of technical quality).

(3) Physical environmental (it remains the same).

(4) Administrative quality (it remains the same). 
These new labels are used in Table 3 and henceforth.

Next, the analysis of the discriminant validity was performed (results are shown in Table 4). As it can be observed, the values for the square roots of each AVE are greater than the off-diagonal elements. Thereby, discriminant validity was confirmed for the HospQual scale.

«Insert Table 4 about here»

Henceforth, the second sample (601 questionnaires) was used: first, to confirm the scale, and second, to analyse the full research model. The standardised solutions for both samples of the HospQual scale (as reflective second order factors) appear summarised in Table 5. As can be observed, the fit indices obtained in the measurement model estimation showed that the variables converged toward the factors established in the CFA. The HospQual scale for the sample of 601 questionnaires showed a correct fitness: $\chi^{2}$ SatorraBentler of $169.830,100$ degrees of freedom, $p$-value of $0.00002, \chi^{2} / \mathrm{df}$ of 1.698, RMSEA of 0.034, and CFI of 0.970 . Noting the global indicators, the global fit was acceptable (Hair et al. 2010).

«Insert Table 5 about here》 
Assessing the research model: The perceived service quality impact on patient satisfaction and the mediating role of fulfilment on quality and satisfaction

The entire research model shown in Figure 2 was analysed using the second sample of 601 questionnaires. Model was estimated again with the robust maximum likelihood method from the asymptotic variance-covariance matrix. The procedure suggested by Satorra and Bentler (2001) was followed, which is based on the robust maximum likelihood estimation. According to Curran, West, and Finch (1996), this method behaves extremely well in nearly every condition across sample size, distribution and model specification. The analysis was performed through Structural Equation Modelling (SEM), using the EQS 6.3 software. The fitness was also good. Table 6 provides the analysis, along with the goodness of fit summary. The model has high explanatory power: the determinant coefficient for satisfaction is 0.635 , proving that the model explains almost $64 \%$ of satisfaction variance. In order to double check for the model fitness, a bootstrapping re-sampling with 300 iterations was then conducted, proving similar global fitness. The results from this bootstrapping analysis are also presented in Table 6 .

The impact of perceived quality on patient's satisfaction is tested. Findings confirm the first hypothesis that perceived quality has a positive impact on customer satisfaction. According to Table 6, patient satisfaction is directly influenced by perceived quality and the standardised coefficient is 0.625 . Findings are in line with previous literature that identified service quality as an antecedent to satisfaction (Cronin \& Taylor, 1992; Thawesaengskulthai et al., 2015).

《Insert Table 6 about here》 
The two remaining hypotheses $\left(\mathrm{H}_{2}\right.$ and $\left.\mathrm{H}_{3}\right)$ are also confirmed in the model. Perceived quality is proved to be a significant antecedent to fulfilment of expectations that in its turn is an antecedent to satisfaction.

The fulfilment of expectations is tested as a mediator between the global perceived quality construct and overall satisfaction. To assess the mediating effect of fulfilment of expectations, the methodology suggested by Baron and Kenny (1986) was adopted and employed in the same way as Bernardo et al. (2012), who used SEMs instead of regression analysis. Preacher and Hayes (2004) recommended the use of SEM for assessing mediation because it offers a reasonable way to control for measurement error as well as some interesting alternative ways to explore the mediation effect.

Baron and Kenny (1986) argued that three conditions must hold in order to establish mediation. They established these through a row of three regression analyses, which can be expressed in the following way when SEMs are used:

(1) The independent variable (perceived quality) significantly predicts the mediator (fulfilment of expectations) (i.e. $a \neq 0$ in Figure 2);

(2) The independent variable (perceived quality) must be shown to predict the dependent variable (satisfaction) (i.e. $c \neq 0$ in Figure 2); and

(3) The mediator (fulfilment of expectations) must significantly predict the dependent variable (satisfaction) (i.e. $b \neq 0$ in Figure 2) controlling for the independent variable (i.e. $\mathrm{c} \neq 0$ in Figure 2).

The three aforementioned conditions are accomplished for the model, confirming that fulfilment of expectations is mediating between perceived quality and satisfaction. 
Additionally, Table 7 shows the decomposition effect between perceived quality and satisfaction for the HospQual scale.

\author{
«Insert Table 7 about here》
}

As it can be observed, the total impact of perceived quality on satisfaction (0.786) is due to a direct effect (0.625) and an indirect effect through the mediating fulfilment of expectations (0.161). These results show that fulfilment of expectations has a relevant function as a predictor of patient satisfaction.

\title{
Discussion
}

The quality of hospital services, as the whole service received by a patient who has required hospitalisation for longer than 24 hours, is a multifactorial construct. Actually, the four dimensions originally proposed by Dagger et al. (2007) are still valid and useful in general terms. However, 10 years after its publication, it required updating. Since then, many Western economies have suffered an economic crisis that has resulted in large cuts to public healthcare services, globalisation has brought about an increase in customer exigencies, as they demand standards of service that are provided in the leading countries, and the broad use of new technologies, which is decreasing their price and, at the same time, is increasing their capacity to provide new services. The four dimensions of quality have a similar weight in reflecting service quality. The loads on a common higher order construct of these dimensions are very similar, showing that none of them can be neglected. This is particularly interesting for managers when they design quality management strategies and allocate resources into actions to enhance each one of these dimensions. 
The HospQual scale is made up from different sources, which vouches for a full integration of existing scales into this new one. It is composed of some items from previous authors (mainly Dagger et al. 2007), some from the local Catalan, Basque and American government instruments, and there is also one item from the authors' proposal. Analysing the items of which each dimension consists, they can be classified in:

(1) Listening to the patient. This dimension encompasses items that directly concern the degree of understanding that the hospital staff has about the patients' concerns.

(2) Staff knowledge. It comprises the knowledge of the staff (particularly the doctors) and their skill to explain details related to the disease and the follow-up treatment, which transmits a positive feeling.

(3) Physical environmental conditions or characteristics, which assure general comfort.

(4) Administrative quality, which is related to those administrative processes in which the patient is involved.

More practical implications come from the fact that the HospQual scale is really short. This instrument enables and simplifies some processes: first, it makes completion of the questionnaire by the patient easy (it only takes a couple of minutes), thus enabling the collection process; second, it allows a quick interpretation and analysis, since a simple global glance at a sheet with the graphs about these indicators (16 items and 4 dimensions) is enough to have a first impression; third, it allows periodic measurement that in turn enables trends that might shed light on taking appropriate managerial decisions to be shown; and fourth, it also enhances benchmarking if it is adopted by the hospitals in the system. Actually, the instrument might be adopted by different types of hospitals, although each one has its own particularities, due to the fact that these 16 items have a broad scope, and they are universal and valid for any hospital, regardless of their differences. 
The research model vouches for a causal linkage between healthcare service quality and patient satisfaction, which is consistent with the literature. This fact has been largely proved in different activity sectors and sociocultural settings, and also in healthcare services (Pollack, 2009; Thawesaengskulthai et al., 2015). The novelty of this research is the analysis of the role of fulfilment of expectations as a mediator between perceived quality and satisfaction. This indirect or mediator effect explains roughly a $20 \%$ of the total effect, what makes fulfilment of expectations a strong predictor of patients' satisfaction.

Two managerial remarks can be drawn from the above fact. The first is that a simple item (fulfilment) provides very valuable information for predicting overall satisfaction. The second is that it is not enough to provide a service free from non-conformities, which would assure a high degree of perceived quality, but it is also crucial to fulfil prior expectations. This implies that managers must know these expectations in order to avoid disappointing these implicit customer desires. Neglecting this fulfilment might erase or dilute the effort made to provide a high standard of quality.

The model also demonstrates a remarkable explanatory capacity, as it explains almost $64 \%$ of satisfaction variance. Thus, the model results are really consistent and useful.

\section{Concluding remarks}

This study aims to propose an up-to-date scale (HospQual) to assess patients' perceived quality of hospital service. To do this an analysis of how fulfilment of patients' expectations mediates the relationship between perceived quality and patient satisfaction is performed. It is believed this topic to be of paramount importance as there is a shortage of instruments able to capture the role of fulfilment of expectations in the healthcare sector. 
Although this study has been carefully conducted, some limitations should be mentioned. First, a single item to measure patient global satisfaction has been used. In this sense, it can be considered that global satisfaction provides enough information to assess the research model, although it would be better to add more items that could provide insight into a patient's satisfaction. Moreover, the research was developed with patients' perceived service quality from a single point in time. Therefore, the present research should be considered a static model. In this line, it could be interesting to develop a longitudinal model to assess the research model at several points in time.

Future research should consider the limitations described above. Data collection from a larger sample in multiple countries or at different points in time (longitudinal) would be an appropriate and effective research approach in the future. A comparative analysis of quality measurement items could also be extended over several types of treatments, nights of hospitalisation, and other issues.

\section{References}

Anderson, E. W., \& Sullivan, M. W. (1993). The antecedents of customer satifaction for firms. Marketing Science, 12(2 Spring), 125-143.

Baron, R. M., \& Kenny, D. A. (1986). The Moderator-Mediator Variable Distinction in Social Psychological Research: Conceptual, Strategic, and Statistical Considerations. Journal of Personality and Social Psychology, 51(6), 1173-1182.

Bernardo, M., Marimon, F., \& Alonso-Almeida, M. D. M. (2012). Functional quality and hedonic quality: A study of the dimensions of e-service quality in online travel agencies. Information and Management, 49(7-8), 342-347.

Bitner, M., \& Hubbert, A. R. (1994). Encounter Satisfaction Versus Overall Satisfaction Versus Quality. In R. T. Rust \& R. L. Oliver (Eds.), Service Quality: New Directions in Theory and Practice (pp. 72-94). Thousand Oaks, CA: Sage Publications.

Bjertnaes, O. A., Sjetne, I. S., \& Iversen, H. H. (2012). Overall patient satisfaction with hospitals: effects of patient-reported experiences and fulfilment of expectations. $B M J$ Quality \& Safety, 21(1), 39-46.

Brady, M. K., \& Cronin, J. J. (2001). Some New Thoughts on Conceptualizing Perceived 
Service Quality: A Hierarchical Approach. Journal of Marketing, 65(3), 34-49.

Brady, M. K., Cronin, J. J., \& Brand, R. R. (2002). Performance-only measurement of service quality: A replication and extension. Journal of Business Research, 55(1), 17 31 .

Centers for Medicare \& Medicaid Services. (2011). Encuesta CAHPS® Sobre Atención Hospitalaria.

Choi, K. S., Cho, W. H., Lee, S., Lee, H., \& Kim, C. (2004). The relationships among quality, value, satisfaction and behavioral intention in health care provider choice: A South Korean study. Journal of Business Research, 57(8), 913-921.

Cronin, J. J., \& Taylor, S. A. (1992). Measuring Service Quality: A Reexamination and Extension. Journal of Marketing, 56(3), 55-68.

Curran, P. J., West, S. G., \& Finch, J. F. (1996). "The robustness of test statistics to nonnormality and specification error in confirmatory factor analysis". Psychological Methods, 1(1): 16-29.

Dagger, T. S., Sweeney, J. C., \& Johnson, L. W. (2007). A Hierarchical Model of Health Service Quality: Scale Development and Investigation of an Integrated Model. Journal of Service Research, 10(2), 123-142.

Dirección de Asistencia Sanitaria (Osakidetza). (2012). Encuesta de satisfacción de pacientes hospitalizados en hospitales de agudos. Departamento de Salud, Gobierno Vasco.

Donabedian, A. (2005). Evaluating the Quality of Medical Care. The Milbank Quarterly, 83(4), 691-729.

Fornell, C., \& Larcker, D. F. (1981). Evaluating Structural Equation Models with Unobservable Variables and Measurement Error. Journal of Marketing Research, 18(3), 39-50.

Grönroos, C. (2006). On defining marketing: finding a new roadmap for marketing. Marketing Theory, 6(4), 395-417.

Haddad, S., Fournier, P., \& Potvin, L. (1998). Measuring lay people's perceptions of the quality of primary health care services in developing countries. Validation of a 20item scale. International Journal for Quality in Health Care, 10(2), 93-104.

Hair, J. F. J., Black, W. C., Babin, B. J., Anderson, R. E., \& Tatham, R. L. (2010). Multivariate Data Analysis. Prentice Hall (7th ed.).

Harman, H. H. (1967). Modern factor analysis (2nd. ed.) Chicago: University of Chicago Press.

Himmel, W., Lippert-Urbanke, E., \& Kochen, M. M. (1997). Are patients more satisfied when they receive a prescription? The effect of patient expectations in general practice. Scandinavian Journal of Primary Health Care, 15(3), 118-122.

Ladhari, R. (2009). A review of twenty years of SERVQUAL research. International Journal of Quality and Service Sciences, 1(2), 172-198.

Lee, D. (2016). HEALTHQUAL: a multi-item scale for assessing healthcare service 
quality. Service Business, in-press. https://doi.org/10.1007/s11628-016-0317-2

Lee, M. A., \& Yom, Y. (2007). A comparative study of patients' and nurses' perceptions of the quality of nursing services, satisfaction and intent to revisit the hospital: a questionnaire survey. International Journal of Nursing Studies, 44(4), 545-555.

Li, M., Lowrie, D. B., Huang, C. Y., Lu, X. C., Zhu, Y. C., Wu, X. H., ... Lu, H. Z. (2015). Evaluating patients' perception of service quality at hospitals in nine Chinese cities by use of the ServQual scale. Asian Pacific Journal of Tropical Biomedicine, 5(6), 497504.

Moliner, M. A. (2009). Loyalty, perceived value and relationship quality in healthcare services. Journal of Service Management, 20(1), 76-97.

Nunnally, J. C., \& Bernstein, I. H. (1994). Psychometric Theory (3rd ed.). New York, NY: McGraw-Hill.

Oliver, R. L. (1997). Satisfaction: A Behavioral Perspective on the Consumer. New York, NY: McGraw-Hill.

Palazzo, C., Jourdan, C., Descamps, S., Nizard, R., Hamadouche, M., Anract, P., Boisgard, S., Galvin, M., Ravaud, P., \& Poiraudeau, S. (2014). Determinants of satisfaction 1 year after total hip arthroplasty: the role of expectations fulfilment. $B M C$ Musculoskeletal Disorders, 15, 53.

Parasuraman, A., Berry, L. L., \& Zeithaml, V. A. (1991). Refinement and Reassessment of the SERQUAL Scale. Journal of Retailing, 67(4), 420-450.

Parasuraman, A., Zeithaml, V. A., \& Berry, L. L. (1988). SERVQUAL: a multiple-item scale for measuring consumer perceptions of service quality. Journal of Retailing, 64(1), 12-40.

Pettersen, K. I., Veenstra, M., Guldvog, B., \& Kolstad, A. (2004). The Patient Experiences Questionnaire: development, validity and reliability. International Journal for Quality in Health Care, 16(6), 453-463.

Peyrot, M., Cooper, P. D., \& Schnapf, D. (1993). Consumer satisfaction and perceived quality of outpatient health services. Journal of Health Care Marketing, 13(1), 24-33.

Pizzi, G., Marzocchi, G. L., Orsingher, C., \& Zammit, A. (2015). The temporal construal of customer satisfaction. Journal of Service Research, 18(4), 484-497.

Podsakoff, P. M., MacKenzie, S. B., Lee, J. Y., \& Podsakoff, N. P. (2003). Common method biases in behavioral research: a critical review of the literature and recommended remedies. Journal of Applied Psychology, 88(5), 879-903.

Pollack, B. L. (2009). Linking the hierarchical service quality model to customer satisfaction and loyalty. Journal of Services Marketing, 23(1), 42-50.

Preacher, K. J., \& Hayes, A. F. (2004). SPSS and SAS procedures for estimating indirect effects in simple mediation models. Behavior Research Methods, Instruments, \& Computers, 36(4), 717-731.

Rao, K. D., Peters, D. H., \& Bandeen-Roche, K. (2006). Towards patient-centered health services in India--a scale to measure patient perceptions of quality. International 
Journal for Quality in Health Care, 18(6), 414-421.

Raposo, M. L., Alves, H. M., \& Duarte, P. A. (2009). Dimensions of service quality and satisfaction in healthcare: A patient's satisfaction index. Service Business, 3(1), 85100.

Ryu, K., Lee, H.-R., \& Kim, W. G. (2012). The influence of the quality of the physical environment, food, and service on restaurant image, customer perceived value, customer satisfaction, and behavioral intentions. International Journal of Contemporary Hospitality Management, 24(2), 200-223.

Satorra, A., \& Bentler, P. M. 2001. A scaled difference chi-square test statistic for moment structure analysis. Psychometrika, 66(4), 507-514.

Servei Català de la Salut (CatSalut). (2015). Enquesta d'Atenció Hospitalària amb internament. Departament de Salut, Generalitat de Catalunya.

Singh, A., \& Prasher, A. (2017). Measuring healthcare service quality from patients' perspective: using Fuzzy AHP application. Total Quality Management \& Business Excellence. https://doi.org/10.1080/14783363.2017.1302794

Sower, V., Duffy, J., Kilbourne, W., Kohers, G., \& Jones, P. (2001). The dimensions of service quality for hospitals: development and use of the KQCAH scale. Health Care Management Review, 26(2), 47-59.

Thawesaengskulthai, N., Wongrukmit, P., \& Dahlgaard, J. J. (2015). Hospital service quality measurement models: patients from Asia, Europe, Australia and America. Total Quality Management \& Business Excellence, 26(10), 1029-1041.

Westbrook, K. W., Babakus, E., \& Grant, C. C. (2014). Measuring Patient-Perceived Hospital Service Quality: Validity and Managerial Usefulness of HCAHPS Scales. Health Marketing Quarterly, 31(2), 97-114.

Yaya, L. H. P., Marimon, F., \& Casadesus, M. (2015). The Mechanisms through Which Certain Variables Influence Customer Loyalty: The Mediating Roles of Perceived Value and Satisfaction. Human Factors and Ergonomics in Manufacturing \& Service Industries, 25(6), 627-637.

Yaya, L. H. P., Marimon, F., \& Casadesús, M. (2016). The expert experience in adopting the E-S-QUAL scale. Total Quality Management \& Business Excellence. https://doi.org/10.1080/14783363.2015.1135728

Zeithaml, V. A., Berry, L. L., \& Parasuraman, A. (1996). The Behavioral Consequences of Service Quality. Journal of Marketing, 60(2), 31-46.

Zhao, X., Lynch Jr., J. G., \& Chen, Q. (2010). Reconsidering Baron and Kenny: Myths and Truths about Mediation Analysis. Journal of Consumer Research, 37(2), 197-206. 


\section{Annex}

The 49 items to assess perceived quality (the main references whence the items were taken are also included). The additional items for "global satisfaction" and "fulfilment of expectations" are included at the bottom.

The definitive HospQual scale items appear in grey (also the two last items that are not configuring the scale).

\begin{tabular}{|c|c|c|c|}
\hline Dimension & Code & Item & Reference \\
\hline \multirow{16}{*}{$\begin{array}{l}\text { Interaction } \\
\text { quality } \\
\text { (Listening to } \\
\text { the patient) }\end{array}$} & INT1 & The doctors at the hospital always listened to what I had to say. & $\begin{array}{c}\text { CatSalut (2015), Centers for Medicare \& } \\
\text { Medicaid Services (2011), Dagger et al. (2007) }\end{array}$ \\
\hline & INT2 & The nursing staff at the hospital always listened to what I had to say. & CatSalut (2015) \\
\hline & INT3 & The doctors kept me informed in language that I could understand. & $\begin{array}{l}\text { Pollack (2009), Centers for Medicare \& } \\
\text { Medicaid Services (2011) }\end{array}$ \\
\hline & INT4 & The nursing staff kept me informed in language that I could understand. & Pollack (2009) \\
\hline & INT5 & $\begin{array}{l}\text { Once in the room, explanations about the functioning of the hospital } \\
\text { were correct. }\end{array}$ & CatSalut (2015) \\
\hline & INT6 & The information received about my disease was correct. & CatSalut (2015) \\
\hline & INT7 & The information received about the tests was correct. & Osakidetza (2012) \\
\hline & INT8 & My relatives and friends received the necessary information. & CatSalut (2015) \\
\hline & INT9 & $\begin{array}{l}\text { The information received from the medical and nursing staff while I was } \\
\text { in the hospital was correct. }\end{array}$ & Osakidetza (2012) \\
\hline & INT10 & Communication via web, email, SMS, etc. was correct. & New item \\
\hline & INT11 & $\begin{array}{l}\text { Hospital professionals who attended to me showed a willingness to help } \\
\text { (eating, dressing, toileting, etc.). }\end{array}$ & Dagger et al. (2007) \\
\hline & INT12 & Doctors understood my needs. & Brady and Cronin (2001) \\
\hline & INT13 & Nursing staff understood my needs. & Brady and Cronin (2001) \\
\hline & INT14 & The treatment in the hospital, in general, was correct. & Dagger et al. (2007) \\
\hline & INT15 & $\begin{array}{l}\text { Respect for my dignity was appropriate (considering the circumstance of } \\
\text { being hospitalised). }\end{array}$ & CatSalut (2015) \\
\hline & INT16 & I didn't feel discriminated against for any reason (sex, race, religion ...). & CatSalut (2015) \\
\hline \multirow{3}{*}{$\begin{array}{c}\text { Technical } \\
\text { quality } \\
\text { (Staff } \\
\text { knowledge) }\end{array}$} & TEC1 & I had the feeling of being in good hands during hospitalisation. & CatSalut (2015) \\
\hline & TEC2 & The information received about my disease was interesting. & CatSalut (2015) \\
\hline & TEC3 & Hospital professionals helped me to control or reduce the pain. & $\begin{array}{c}\text { CatSalut (2015), Centers for Medicare \& } \\
\text { Medicaid Services (2011) }\end{array}$ \\
\hline
\end{tabular}




\begin{tabular}{|c|c|c|c|}
\hline & TEC4 & $\begin{array}{l}\text { The knowledge and skills of medical personnel who treated me were } \\
\text { adequate. }\end{array}$ & Osakidetza (2012) \\
\hline & TEC5 & I was diagnosed in a time period that I consider correct. & CatSalut (2015), Dagger et al. (2007) \\
\hline & TEC6 & $\begin{array}{l}\text { The hospital employed all the necessary resources to ensure the success } \\
\text { of my cure. }\end{array}$ & Donabedian (2005) \\
\hline & TEC7 & They clearly explained to me how to take the medicines at home. & $\begin{array}{l}\text { Osakidetza (2012), Centers for Medicare \& } \\
\text { Medicaid Services (2011) }\end{array}$ \\
\hline & TEC8 & I understood the medical recommendations received in hospital. & Dagger et al. (2007) \\
\hline & TEC9 & I feel hopeful as a result of having treatment at the hospital. & Dagger et al. (2007) \\
\hline & TEC10 & $\begin{array}{l}\text { Coming to the hospital has increased my chances of improving my } \\
\text { health. }\end{array}$ & Dagger et al. (2007) \\
\hline & TEC11 & $\begin{array}{l}\text { I was correctly informed about health centres where I should go to } \\
\text { continue my curative process. }\end{array}$ & CatSalut (2015) \\
\hline & TEC12 & I participated in the decisions about my diagnosis and treatment. & CatSalut (2015) \\
\hline \multirow{12}{*}{$\begin{array}{l}\text { Physical } \\
\text { environment }\end{array}$} & PHY1 & The general condition of the hospital was excellent. & Dagger et al. (2007) \\
\hline & PHY2 & The hospital had up-to-date equipment. & Dagger et al. (2007) \\
\hline & PHY3 & The employees were well dressed and clean. & Dagger et al. (2007) \\
\hline & PHY4 & $\begin{array}{l}\text { Hospital food was good (considering that the diet has to suit the clinical } \\
\text { requirements). }\end{array}$ & CatSalut (2015) \\
\hline & PHY5 & Signalling within the hospital was correct. & New item \\
\hline & PHY6 & The room where I was hospitalised was comfortable. & $\begin{array}{c}\text { Osakidetza (2012), Dagger et al. (2007), Brady } \\
\text { and Cronin (2001) }\end{array}$ \\
\hline & PHY7 & Cleanliness of my room and bathroom was good. & $\begin{array}{l}\text { Dagger et al. (2007), Centers for Medicare \& } \\
\text { Medicaid Services (2011) }\end{array}$ \\
\hline & PHY8 & $\begin{array}{l}\text { Respect for my privacy was adequate (considering the circumstances of } \\
\text { being hospitalised). }\end{array}$ & CatSalut (2015) \\
\hline & PHY9 & The temperature in the room was pleasant. & Brady and Cronin (2001) \\
\hline & PHY10 & The lighting in the room was adequate. & Dagger et al. (2007) \\
\hline & PHY11 & The peacefulness that I had to rest and sleep at night was adequate. & $\begin{array}{c}\text { CatSalut (2015), Centers for Medicare \& } \\
\text { Medicaid Services (2011) }\end{array}$ \\
\hline & PHY12 & The noise level was acceptable. & Dagger et al. (2007) \\
\hline
\end{tabular}




\begin{tabular}{|c|c|l|c|}
\hline \multirow{4}{*}{} & ADM1 & $\begin{array}{l}\text { The time period between the decision to be hospitalised and } \\
\text { hospitalisation was reasonable }\end{array}$ & Osakidetza (2012), Donabedian (2005) \\
\cline { 2 - 4 } & ADM2 & $\begin{array}{l}\text { The waiting time after pressing the bell to alert the nursing staff was } \\
\text { reasonable. }\end{array}$ & CatSalut (2015) \\
\cline { 2 - 5 } & ADM3 & The hospital reports did not contain errors. & Donabedian (2005) \\
\cline { 2 - 4 } $\begin{array}{c}\text { Administration } \\
\text { quality }\end{array}$ & ADM4 & The check-in process at the hospital was quick and efficient. & Dagger al. (2007) \\
\cline { 2 - 5 } & ADM5 & $\begin{array}{l}\text { The organisation and coordination between hospital professionals who } \\
\text { attended to me were correct. }\end{array}$ & Dagger et al. (2007), Brady and Cronin (2001) \\
\cline { 2 - 5 } & ADM6 & Relatives and friends who visited me felt well attended to. & New item \\
\cline { 2 - 5 } & ADM7 & Hospital schedules for eating, sleeping, etc. were suitable. & Natetza (2012) \\
\cline { 2 - 5 } & ADM9 & The realisation of administrative processes was correct. & $\begin{array}{l}\text { The tests performed during my hospitalisation were well-planned and } \\
\text { coordinated. }\end{array}$ \\
\hline $\begin{array}{c}\text { Global } \\
\text { satisfaction }\end{array}$ & GS & I am satisfied with the hospital and services received. & CatSalut (2015) \\
\hline $\begin{array}{c}\text { Fulfilment of } \\
\text { expectations }\end{array}$ & FE & The hospital care has fulfilled my expectations. & New item \\
\hline
\end{tabular}


Table 1. Demographic characteristics of the samples

\begin{tabular}{|c|c|c|c|c|}
\hline & \multicolumn{2}{|c|}{ Sample $1(n=200)$} & \multicolumn{2}{|c|}{ Sample $2(n=601)$} \\
\hline & Number & $\%$ & Number & $\%$ \\
\hline \multicolumn{5}{|l|}{ Gender } \\
\hline \multirow{3}{*}{$\begin{array}{r}\text { Female } \\
\text { Male } \\
\text { Total }\end{array}$} & 100 & 50.0 & 373 & 62.1 \\
\hline & 100 & 50.0 & 228 & 37.9 \\
\hline & 200 & 100.0 & 601 & 100.0 \\
\hline \multicolumn{5}{|l|}{ Age } \\
\hline \multirow{6}{*}{$\begin{array}{r}\text { Less than } 18 \text { years old } \\
\text { Between } 18 \text { and } 29 \text { years old } \\
\text { Between } 30 \text { and } 44 \text { years old } \\
\text { Between } 45 \text { and } 59 \text { years old } \\
\text { More than } 60 \text { years old } \\
\text { Total }\end{array}$} & 0 & 0.0 & 0 & 0.0 \\
\hline & 26 & 13.0 & 145 & 24.1 \\
\hline & 57 & 28.5 & 214 & 35.6 \\
\hline & 49 & 24.5 & 126 & 21.0 \\
\hline & 68 & 34.0 & 116 & 19.3 \\
\hline & 200 & 100.0 & 601 & 100.0 \\
\hline \multicolumn{5}{|l|}{ Hospitalisation year } \\
\hline 2016 & 48 & 24.0 & 226 & 37.6 \\
\hline 2015 & 82 & 41.0 & 187 & 31.1 \\
\hline 2014 & 70 & 35.0 & 188 & 31.3 \\
\hline Total & 200 & 100.0 & 601 & 100.0 \\
\hline \multicolumn{5}{|l|}{ Nights that the hospitalisation lasted } \\
\hline \multirow{5}{*}{$\begin{array}{r}1 \text { night } \\
2 \text { nights } \\
\text { Between } 3 \text { and } 5 \text { nights } \\
\text { More than } 6 \text { nights } \\
\text { Total }\end{array}$} & 47 & 23.5 & 134 & 22.3 \\
\hline & 49 & 24.5 & 84 & 14.0 \\
\hline & 60 & 30.0 & 235 & 39.1 \\
\hline & 44 & 22.0 & 148 & 24.6 \\
\hline & 200 & 100.0 & 601 & 100.0 \\
\hline \multicolumn{5}{|l|}{ Type of hospital admission } \\
\hline \multirow{4}{*}{$\begin{array}{r}\text { Urgent } \\
\text { Scheduled } \\
\text { Other } \\
\text { Total }\end{array}$} & 84 & 42.0 & 333 & 55.4 \\
\hline & 112 & 56.0 & 252 & 41.9 \\
\hline & 4 & 2.0 & 16 & 2.7 \\
\hline & 200 & 100.0 & 601 & 100.0 \\
\hline \multicolumn{5}{|l|}{ Type of disease } \\
\hline \multirow{14}{*}{$\begin{array}{r}\text { Infectious disease } \\
\text { Endocrine disease, nutrition, metabolic and immunity disorder } \\
\text { Blood disease } \\
\text { Mental, behavioural and neurological development disorder } \\
\text { Nervous system and sense organs disease } \\
\text { Circulatory system disease } \\
\text { Respiratory system disease } \\
\text { Digestive system disease } \\
\text { Genitourinary system disease } \\
\text { Pregnancy and childbirth } \\
\text { Skin and subcutaneous tissue disease } \\
\text { Injury and poisoning } \\
\text { Other disease } \\
\text { Total }\end{array}$} & 4 & 2.0 & 60 & 10.0 \\
\hline & 11 & 5.5 & 39 & 6.5 \\
\hline & 4 & 2.0 & 23 & 3.8 \\
\hline & 3 & 1.5 & 15 & 2.5 \\
\hline & 6 & 3.0 & 22 & 3.7 \\
\hline & 13 & 6.5 & 27 & 4.5 \\
\hline & 12 & 6.0 & 45 & 7.5 \\
\hline & 27 & 13.5 & 47 & 7.8 \\
\hline & 19 & 9.5 & 31 & 5.1 \\
\hline & 15 & 7.5 & 110 & 18.3 \\
\hline & 4 & 2.0 & 13 & 2.2 \\
\hline & 23 & 11.5 & 84 & 14.0 \\
\hline & 59 & 29.5 & 85 & 14.1 \\
\hline & 200 & 100.0 & 601 & 100.0 \\
\hline
\end{tabular}


Table 2. Four EFAs using the principal component analysis and the varimax rotation (based on Sample 1)

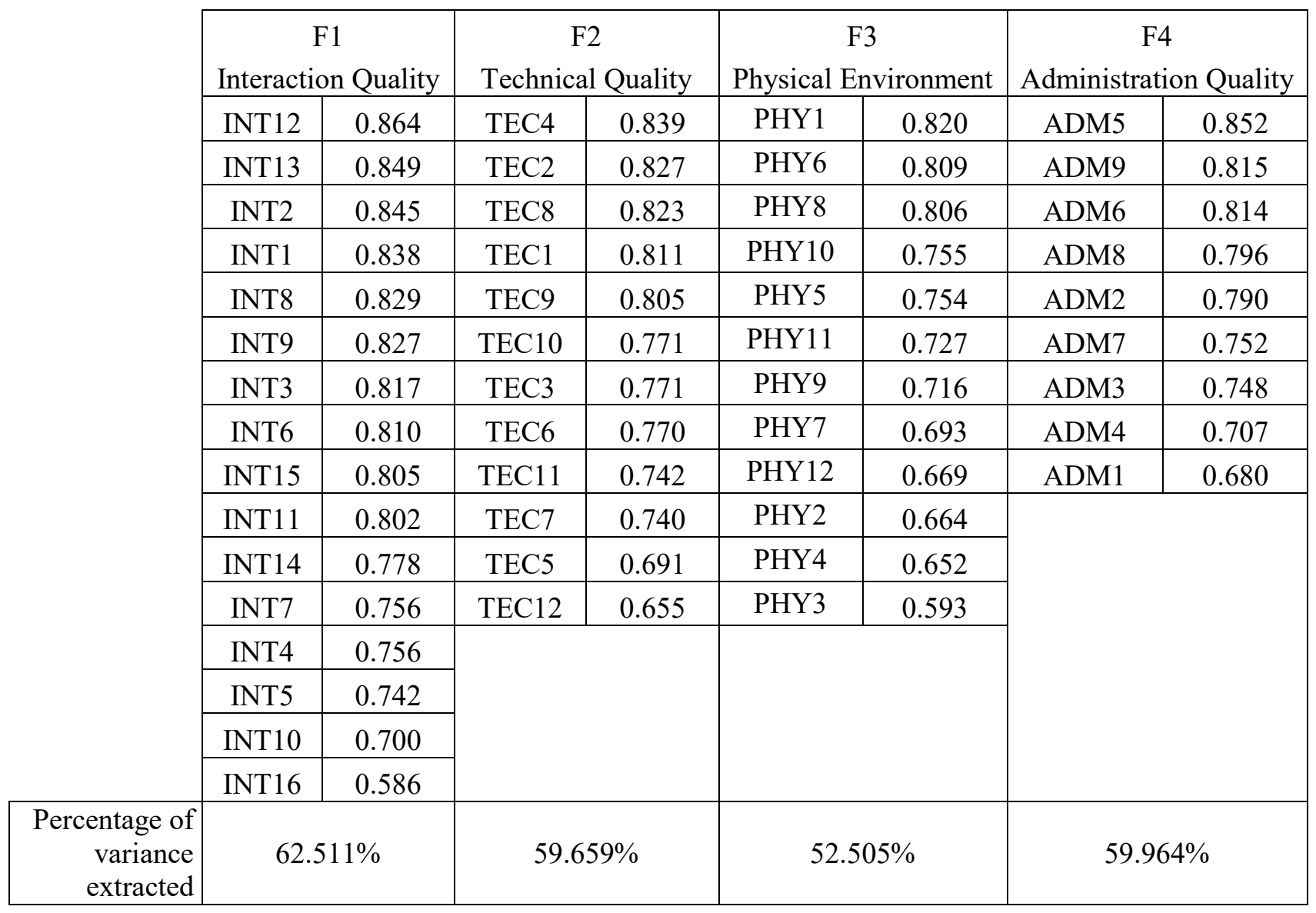


Table 3. Loads of the four CFAs and statistics for the reliability analyses of the HospQual scale (based on Sample 1)

\begin{tabular}{|c|c|c|c|c|c|c|c|c|}
\hline & \multicolumn{2}{|c|}{$\begin{array}{c}\text { F1 } \\
\text { Listening to the } \\
\text { patient }\end{array}$} & \multicolumn{2}{|c|}{$\begin{array}{c}\text { F2 } \\
\text { Staff knowledge }\end{array}$} & \multicolumn{2}{|c|}{$\begin{array}{c}\text { F3 } \\
\text { Physical } \\
\text { Environment }\end{array}$} & \multicolumn{2}{|c|}{$\begin{array}{c}\mathrm{F} 4 \\
\text { Administration } \\
\text { Quality }\end{array}$} \\
\hline & INT12 & 0.902 & TEC4 & 0.899 & PHY6 & 0.865 & ADM5 & 0.893 \\
\hline & INT13 & 0.887 & TEC2 & 0.883 & PHY1 & 0.864 & ADM9 & 0.854 \\
\hline & INT2 & 0.883 & TEC8 & 0.856 & PHY8 & 0.837 & ADM6 & 0.840 \\
\hline & INT1 & 0.877 & TEC1 & 0.804 & PHY10 & 0.781 & ADM8 & 0.821 \\
\hline Alpha Cronbach & \multicolumn{2}{|c|}{0.909} & \multicolumn{2}{|c|}{0.883} & \multicolumn{2}{|c|}{0.858} & \multicolumn{2}{|c|}{0.874} \\
\hline $\begin{array}{l}\text { Range of Cronbach's } \\
\text { alpha if one item is } \\
\text { removed }\end{array}$ & \multicolumn{2}{|c|}{$0.872-0.889$} & \multicolumn{2}{|c|}{$0.826-0.879$} & \multicolumn{2}{|c|}{$0.801-0.849$} & \multicolumn{2}{|c|}{$0.813-0.856$} \\
\hline $\begin{array}{l}\text { Range of correlations } \\
\text { between items and total } \\
\text { corrected scale }\end{array}$ & \multicolumn{2}{|c|}{$0.779-0.822$} & \multicolumn{2}{|c|}{$0.669-0.807$} & \multicolumn{2}{|c|}{$0.627-0.744$} & \multicolumn{2}{|c|}{$0.686-0.794$} \\
\hline Composite Reliability & \multicolumn{2}{|c|}{0.937} & \multicolumn{2}{|c|}{0.920} & \multicolumn{2}{|c|}{0.904} & \multicolumn{2}{|c|}{0.914} \\
\hline $\begin{array}{l}\text { Average Variance } \\
\text { Extracted }\end{array}$ & \multicolumn{2}{|c|}{0.787} & \multicolumn{2}{|c|}{0.742} & \multicolumn{2}{|c|}{0.701} & \multicolumn{2}{|c|}{0.727} \\
\hline
\end{tabular}

All loads are significant at $\mathrm{p}$-value $=0.01$. 
Table 4. Correlation matrix of latent factors. Discriminant analysis and average results in the HospQual scale (based on Sample 1)

\begin{tabular}{|l|c|c|c|c|}
\cline { 2 - 3 } \multicolumn{1}{c|}{} & $\begin{array}{c}\text { F1 } \\
\text { Listening to } \\
\text { the patient }\end{array}$ & $\begin{array}{c}\text { F2 } \\
\text { Staff } \\
\text { knowledge }\end{array}$ & $\begin{array}{c}\text { F3 } \\
\text { Physical } \\
\text { Environment }\end{array}$ & $\begin{array}{c}\text { F4 } \\
\text { Administration } \\
\text { Quality }\end{array}$ \\
\hline F1 Interaction Quality & 0.887 & & & \multirow{2}{*}{} \\
\cline { 1 - 3 } F2 Technical Quality & 0.828 & 0.861 & & \\
\hline F3 Physical Environment & 0.759 & 0.706 & 0.837 & 0.852 \\
\hline F4 Administration Quality & 0.859 & 0.831 & 0.777 & \\
\hline
\end{tabular}

All correlations are significant at the 0.01 level (bilateral).

Diagonal elements are the square roots of the average extracted. 
Table 5. Standardised solutions for the scale as a second order factor (based on Sample 2)

\begin{tabular}{|c|c|c|c|c|}
\hline Dimension & Items & Load & t-value & $r^{2}$ \\
\hline \multirow{4}{*}{ F1 Listening to the patient } & INT12 & 0.737 & - & 0.543 \\
\hline & INT13 & 0.708 & 12.95 & 0.502 \\
\hline & INT2 & 0.723 & 12.63 & 0.523 \\
\hline & INT1 & 0.750 & 13.65 & 0.563 \\
\hline \multirow{4}{*}{ F2 Staff knowledge } & TEC4 & 0.709 & - & 0.503 \\
\hline & TEC2 & 0.661 & 11.11 & 0.436 \\
\hline & TEC8 & 0.651 & 11.48 & 0.423 \\
\hline & TEC1 & 0.769 & 13.11 & 0.591 \\
\hline \multirow{4}{*}{ F3 Physical Environment } & PHY6 & 0.719 & - & 0.518 \\
\hline & PHY1 & 0.759 & 14.79 & 0.576 \\
\hline & PHY8 & 0.708 & 14.80 & 0.502 \\
\hline & PHY 10 & 0.706 & 14.29 & 0.498 \\
\hline \multirow{4}{*}{ F4 Administration Quality } & ADM5 & 0.655 & - & 0.429 \\
\hline & ADM9 & 0.728 & 12.42 & 0.531 \\
\hline & ADM6 & 0.690 & 11.73 & 0.475 \\
\hline & ADM8 & 0.665 & 11.80 & 0.442 \\
\hline \multirow{4}{*}{ F5 Perceived Quality } & F1 LIS & 0.921 & - & 0.848 \\
\hline & F2 STF & 0.926 & 11.39 & 0.857 \\
\hline & F3 PHY & 0.800 & 11.53 & 0.640 \\
\hline & F4 AQU & 0.937 & 12.08 & 0.878 \\
\hline \multicolumn{5}{|l|}{ Goodness of fit summary } \\
\hline \multicolumn{2}{|c|}{ Satorra-Bentler scaled $\chi^{2}$} & \multicolumn{3}{|c|}{169.830} \\
\hline \multicolumn{2}{|c|}{ Degrees of freedom } & \multicolumn{3}{|c|}{100} \\
\hline \multicolumn{2}{|r|}{$p$-value } & \multicolumn{3}{|c|}{0.00002} \\
\hline \multicolumn{2}{|r|}{$\chi^{2 / d f}$} & \multicolumn{3}{|c|}{1.698} \\
\hline \multicolumn{2}{|c|}{ Comparative fit index (CFI) } & \multicolumn{3}{|c|}{0.970} \\
\hline \multicolumn{2}{|c|}{ Root mean-square error of approximation (RMSEA) } & \multicolumn{3}{|c|}{0.034} \\
\hline \multicolumn{2}{|c|}{$90 \%$ confidence interval of RMSEA } & \multicolumn{3}{|c|}{$(0.025,0.043)$} \\
\hline
\end{tabular}


Table 6. Research model solutions and goodness of fit summary (based on Sample 2), including a bootstrap analysis.

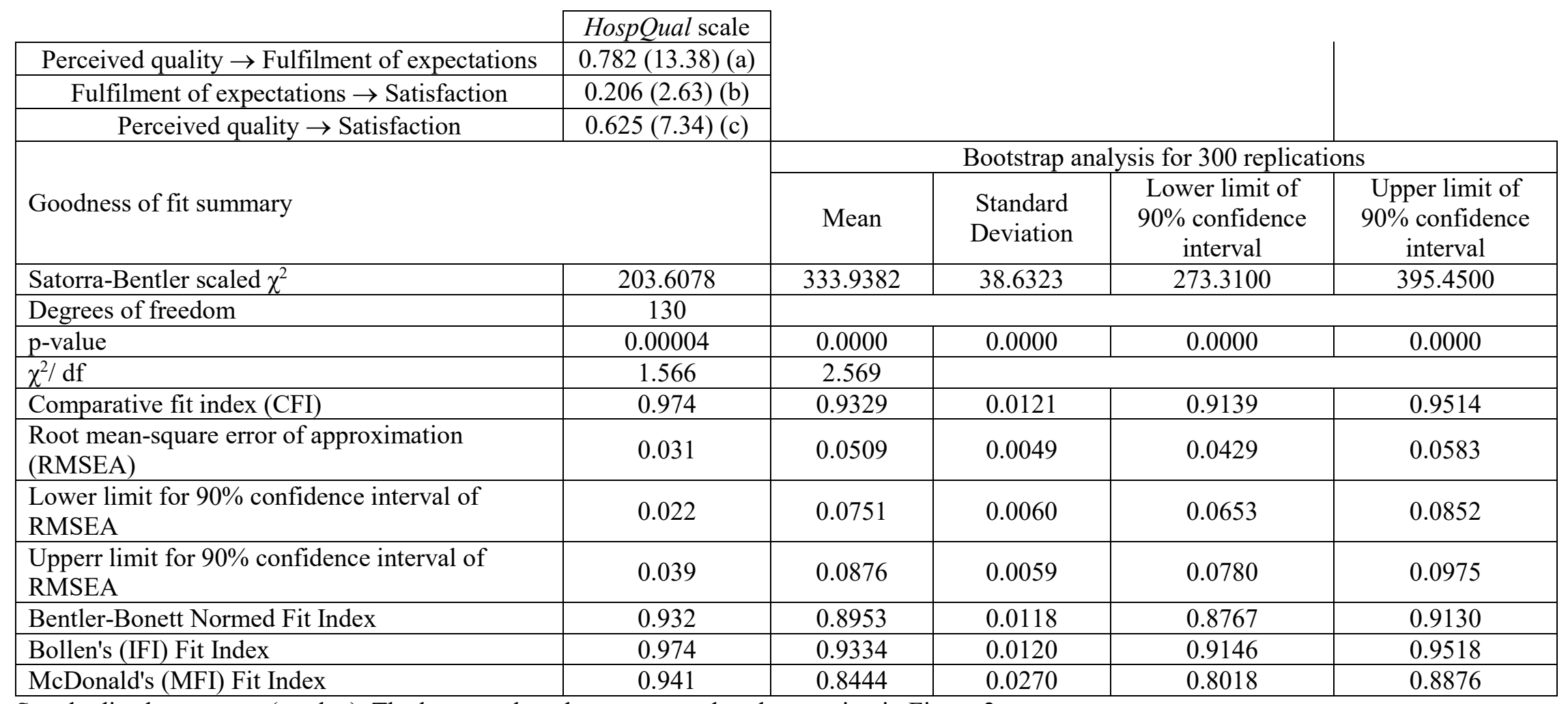

Standardized parameter (t-value). The letters $\mathrm{a}, \mathrm{b}$ and $\mathrm{c}$, correspond to the notation in Figure 2. 
Table 7. Decomposition of the effect of perceived quality on satisfaction (based on Sample 2)

\begin{tabular}{|l|l|c|}
\cline { 3 - 3 } \multicolumn{2}{c|}{} & HospQual scale \\
\hline \multirow{3}{*}{$\begin{array}{l}\text { Perceived quality } \rightarrow \\
\text { Satisfaction }\end{array}$} & Direct effect & $0.625(7.34)(\mathrm{c})$ \\
\cline { 2 - 3 } & Indirect effect & $0.161(\mathrm{a} * \mathrm{~b})$ \\
\cline { 2 - 3 } & Total effect & $0.786(5.53)$ \\
\hline
\end{tabular}

Standardized parameter (t-value).

The letters $\mathrm{a}, \mathrm{b}$ and $\mathrm{c}$, correspond to the notation in Figure 2. 
Figure 1. Conceptual research model and hypotheses

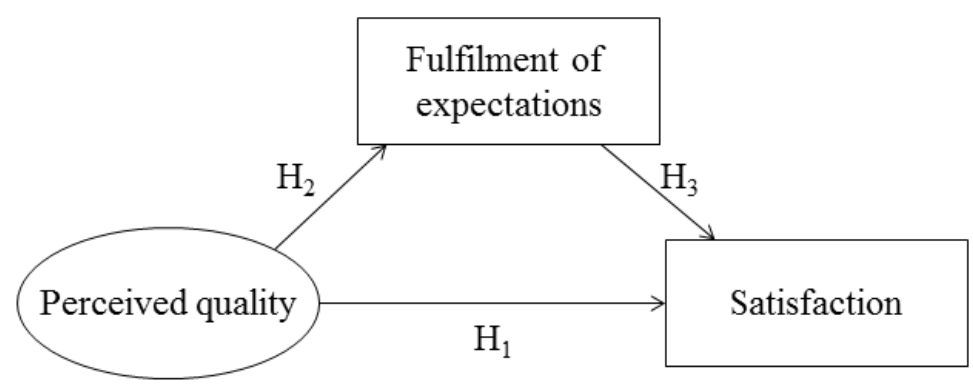


Figure 2. Full research model

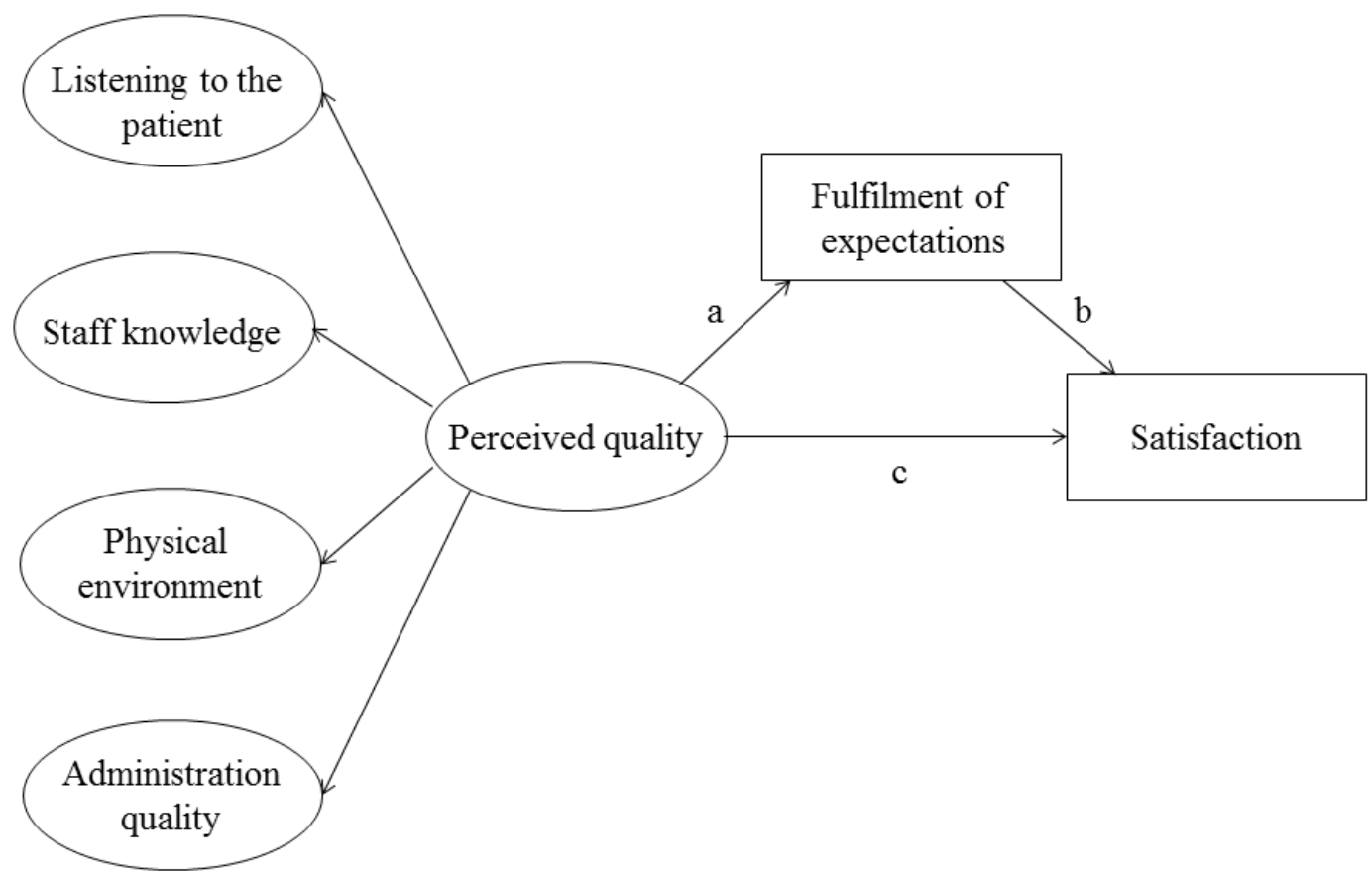

